\title{
To Find Out The Risk Factors And Complications Associated With Obesity Among Adults Population Of Namkum Block in Ranchi District.
}

\author{
Anit Kujur ${ }^{1}$, Vidyasagar ${ }^{2}$, Vivek Kashyap ${ }^{3}$ \\ ${ }^{1}$ Junior Resident, ${ }^{2}$ Associate Professor, ${ }^{3}$ Professor \& Head, Department of PSM, \\ Rajendra Institute of Medical Sciences (RIMS), Ranchi, India
}

\begin{abstract}
:
Introduction : Obesity can be seen as the first wave of a defined cluster of non-communicable diseases has reached epidemic proportion in developed and developing nations.

Aims And Objectives: To find out the risk factors and complications associated with Obesity among adults population of Namkum block in Ranchi District.

Material And Methods : Cross-sectional community based. Study period was September 2013 to December 2015.

Statistical Analysis: Data was entered into Microsoft excel sheet(2007 version) and analyzed using SPSS version 20.

Results: A total number of 500 study subjects were included in the study of whom 310(62\%) were females and 190(38\%) were males. Majority i.e.157(31.4\%) of study subjects were in the age group of 20-30 years.The mean age of males was $38.71+17.17$ years and of females $45.18+19.43$ years.
\end{abstract}

Conclusion: Obesity is commonly seen as a complex multi factorial disease.

Keywords: Obesity, Obesity Risk Factors .

\section{Introduction}

Obesity is increasing at an alarming rate throughout the world.The World Health Organization has described obesity as one of today's most neglected public health problems, affecting every region of the globe $^{(1)}$.Obesity is not a recent phenomenon. The health hazards associated with obesity were well known to the ancient Greek physician Hippocrates, who stated that 'sudden death is more common in those who are naturally fat than lean'. The term 'obesity' is derived from the Latin word Obesus, meaning 'having eaten until fat.'Societal changes and worldwide nutrition transition are driving the obesity epidemic. Economic growth, modernization, urbanization and globalization of food markets are just some of the forces . Overweight and obesity is increasing worldwide. It has reached epidemic proportion in developed and developing nations. Obesity is a risk factor for chronic diseases particularly type 2 diabetes, hypertension, dyslipidemia, cancer. Change in life style, dietary habits and physical inactivity are the leading causes for obesity. Obesity is seen as a symbol of wealth and status in many societies of the world ${ }^{(2)}$.In view of the rapidly growing numbers of elderly people in many developed countries, this has important health implications in terms of health promotion and treatment targets. Obesity also contributes to functional decline and disability in elderly people ${ }^{(3,4)}$.Obesity represents a serious health concern that needs to be addressed to improve the health and well-being of the present and the future elderly population .The normal ageing is characterized by decrease in bone and muscles mass, increase in fat mass and more central distribution of adipose tissue. ${ }^{(5,6)}$ These changes can have important consequences on the profile of risk factors for developing metabolic syndrome. ${ }^{(7)}$

Rising prevalence of obesity may be attributed to various factors, like sedentary life-style ${ }^{(8)}$ unhealthy food habits, cultural practices and increasing affluence of middle class population ${ }^{(9,10,11,12)}$.

Table showing Modifiable and non- modifiable risk factors of obesity

\begin{tabular}{|l|l|}
\hline Non modifiable risk factors & Modifiable risk factors \\
\hline Age & Dietary factors \\
Sex & Physical inactivity (sedentary life style) \\
Genetic factors & Psycho social factors \\
Ethnicity & Socioeconomic status \\
Familial tendency & Alcohol consumption \\
& Endocrine factors \\
& Oral contraceptive and other drugs \\
\hline
\end{tabular}




\section{Aims and Objectives}

To Find Out The Risk Factors and Complications Associated With Obesity Among Adults Population Of Namkum Block In Ranchi District.

\section{Material and Methods}

Cross-sectional community based study was conducted at areas of Namkum Block of Ranchi District. Study period was from September 2013 to December 2015.The final study protocol, including the final version of the questionnaire and Consent forms were approved by the Ethics Committee of the RIMS, medical college, Ranchi before enrolment of any subject into the study. The total sample size obtained was 500.

Sampling technique: Cluster sampling method is used in the present study.Total number of villages was obtained by Census 2011.Listing of all villages of Namkum was done. One village was considered as one cluster.Population of each village was enumerated and cumulative total of population was derived. Number of clusters (villages) surveyed were fixed to 6 and were selected for sampling by random number table and from these villages persons 20 years and above both male and female those willing to participate were interviewed.

Method of collection of data: House to house visit was carried out to identify the eligible adults. Rapport was established with the community with the help of medico-social work. 500 adults were surveyed and the rest were not included as they did not give consent for the study or they were unavailable at the time of study. Participants were declared unavailable if they were not available even after two house visits . On entering chosen cluster, first lane was chosen randomly using random number table. All the houses in the chosen lane were visited and data was collected from eligible study subjects who gave consent with use of pre tested Questionnaire to get the information regarding the socio-demographic determinants (age, sex, education, marital status, occupation, income), personal habits (tobacco use, alcohol and other habits). Height, weight and waist circumference were measured using stadiometer, weighing machine and non-stretchable measuring tape respectively. This was continued till the target from each cluster (06) was met.

Body mass index:Calculated by Quetlet's index, i.e by dividing weight in kilogram by square of height in meters.( Source: Adapted from WHO 1995, WHO 2000 and WHO 2004).

- Underweight : BMI < 18.5

- Normal : BMI $18.5-22.9$

- Overweight : BMI $23-24.9$

- Obese I : BMI 25-29.99

- Obese II : BMI> 30.

Calculation of prevalence of obesity: Prevalence $\%=$ Number of obese subjects $\times 100$ Total numbers of subjects covered

Statistical analysis of data: Data was entered into Microsoft excel sheet and analyzed using SPSS Version 20. Results were expressed in Mean, Percentages ,Chi-square was applied to find out the statistical significance of factors. All the factors which indicated statistical significance in the univariate analysis were taken for multivariate analysis. Multivariate analysis used was Binary logistic regression analysis. The statistical significance was evaluated at $95 \%$ level $(\mathrm{p}<0.05)$

\section{Results}

Table 1: Socio-demographic characteristics of the study subjects

\begin{tabular}{|l|l|l|}
\hline \multicolumn{2}{|l|}{ Socio- demographic Factors } & $\begin{array}{l}\text { Frequency }(\%) \\
\mathrm{n}=500\end{array}$ \\
\hline \multirow{3}{*}{ Gender } & Male & $190(38 \%)$ \\
\cline { 2 - 3 } & Female & $310(62 \%)$ \\
\hline \multirow{5}{*}{ Oge group } & $20-30$ & $157(31.4 \%)$ \\
\cline { 2 - 3 } & $31-40$ & $88(17.6 \%)$ \\
\cline { 2 - 3 } & $41-50$ & $66(13.4 \%)$ \\
\cline { 2 - 3 } & $51-60$ & $46(9.2 \%)$ \\
\cline { 2 - 3 } & $61-70$ & $101(20.2 \%)$ \\
\cline { 2 - 3 } & $71-80$ & $19(3.8 \%)$ \\
\cline { 2 - 3 } & $>80$ & $23(4.6 \%)$ \\
\hline \multirow{5}{*}{ Occupation } & Unemployed & $16(3.2 \%)$ \\
\cline { 2 - 3 } & Daily wages Earner & $25(5 \%)$ \\
\cline { 2 - 3 } & Agriculture & $14(2.8 \%)$ \\
\cline { 2 - 3 } & Retired & $95(19 \%)$ \\
\cline { 2 - 3 } & Service & $50(10 \%)$ \\
\cline { 2 - 3 } & Business & $105(21 \%)$ \\
\cline { 2 - 3 } & Housewife/Househusband & $145(29 \%)$ \\
\cline { 2 - 3 } & Students & $50(10 \%)$ \\
\hline & Literate & $387(77 \%)$ \\
\hline
\end{tabular}


To Find Out The Risk Factors And Complications Associated With Obesity Among Adults ...

\begin{tabular}{|l|l|l|}
\hline Education & Illiterate & $115(33 \%)$ \\
\hline \multirow{5}{*}{ Religion } & Hindu & $254(50.8 \%)$ \\
\cline { 2 - 3 } & Sarna* & $217(43.4 \%)$ \\
\cline { 2 - 3 } & Christian & $26(5.2 \%)$ \\
\cline { 2 - 3 } & Muslim & $3(0.6 \%)$ \\
\hline \multirow{5}{*}{ Marital status } & Married & $467(93.4 \%)$ \\
\cline { 2 - 3 } & Unmarried & $19(3.8 \%)$ \\
\cline { 2 - 3 } & Divorced/Widow/Separated & $14(2.8 \%)$ \\
\hline \multirow{5}{*}{ Socio-economic class } & Nuclear & $154(30.8 \%)$ \\
\cline { 2 - 3 } & Joint & $312(62.4 \%)$ \\
\cline { 2 - 3 } & Extended & $34(6.8 \%)$ \\
\hline & Upper class & $11(2.2 \%)$ \\
\cline { 2 - 3 } & Upper middle Class & $108(21.6 \%)$ \\
\cline { 2 - 3 } & Middle Class & $100(20.1 \%)$ \\
\cline { 2 - 3 } & Lower middle Class & $207(41.4 \%)$ \\
\cline { 2 - 3 } & Lower & $74(14.7 \%)$ \\
\hline
\end{tabular}

*Sarna= Local religion of Jharkhand

Table 2: Distribution of study subjects according to BMI (WHO Asia-pacific guidelines

\begin{tabular}{|l|l|l|l|}
\hline BMI & Male & Female & Total \\
\hline$<18.5$ & $8(25.8 \%)$ & $23(74.2 \%)$ & $31(6.2 \%)$ \\
\hline $18.5-22.9$ & $82(30.5 \%)$ & $186(69.5 \%)$ & $268(53.7 \%)$ \\
\hline $23-24.99$ & $41(45 \%)$ & $50(55 \%)$ & $91(18.2 \%)$ \\
\hline$>25$ & $59(53.6 \%)$ & $51(46.4 \%)$ & $110(21.9 \%)$ \\
\hline Total & $190(38 \%)$ & $310(62 \%)$ & $500(100 \%)$ \\
\hline
\end{tabular}

Table 3: Prevalence of obesity across age group.

\begin{tabular}{|c|c|c|c|c|c|}
\hline \multicolumn{3}{|c|}{ Age (in yrs) } & Obese & Non -obese & Total \\
\hline & \multirow[t]{2}{*}{$20-30$} & Count & 30 & 127 & 157 \\
\hline & & $\%$ & $27.3 \%$ & $32.6 \%$ & $31.4 \%$ \\
\hline & \multirow[t]{2}{*}{$31-40$} & Count & 8 & 80 & 88 \\
\hline & & $\%$ & $7.3 \%$ & $20.5 \%$ & $17.6 \%$ \\
\hline & \multirow[t]{2}{*}{$41-50$} & Count & 35 & 31 & 66 \\
\hline & & $\%$ & $31.8 \%$ & $7.9 \%$ & $13.2 \%$ \\
\hline & \multirow[t]{2}{*}{$51-60$} & Count & 11 & 35 & 46 \\
\hline & & $\%$ & $10.0 \%$ & $9.0 \%$ & $9.2 \%$ \\
\hline & \multirow[t]{2}{*}{$61-70$} & Count & 10 & 91 & 101 \\
\hline & & $\%$ & $9.1 \%$ & $23.3 \%$ & $20.2 \%$ \\
\hline & \multirow[t]{2}{*}{$71-80$} & Count & 11 & 8 & 19 \\
\hline & & $\%$ & $10.0 \%$ & $2.1 \%$ & $3.8 \%$ \\
\hline & \multirow[t]{2}{*}{$81-90$} & Count & 5 & 18 & 23 \\
\hline & & $\%$ & $4.5 \%$ & $4.6 \%$ & $4.6 \%$ \\
\hline \multirow{2}{*}{\multicolumn{2}{|c|}{ Total }} & Count & 110 & 390 & 500 \\
\hline & & $\%$ & $100.0 \%$ & $100.0 \%$ & $100.0 \%$ \\
\hline \multicolumn{4}{|c|}{ Chi square $=69.326$} & \multicolumn{2}{|l|}{$\mathrm{P}$ value $=.001$} \\
\hline
\end{tabular}

Table4: Prevalence of obesity across the Socioeconomic status.

\begin{tabular}{|l|l|l|l|}
\hline Socio-economic class & Obese & Non-Obese & Total \\
\hline Upper class & $4(3.6 \%)$ & $7(1.7 \%)$ & $11(2.2 \%)$ \\
\hline Upper Middle class & $30(27.2 \%)$ & $78(20 \%)$ & $108(21.6 \%)$ \\
\hline Middle class & $35(31.8 \%)$ & $65(16.6 \%)$ & $100(20.1 \%)$ \\
\hline Lower Middle Class & $31(28.2 \%)$ & $176(45.1 \%)$ & $207(41.4 \%)$ \\
\hline Lower class & $9(9.2 \%)$ & $65(16.6 \%)$ & $74(14.7 \%)$ \\
\hline Total & $110(21.9 \%)$ & $390(78.1 \%)$ & $500(100 \%)$ \\
\hline & Chi square $=23.540$ & P value $=.001$ & \\
\hline
\end{tabular}

Table 5: Prevalence of obesity across the religion

\begin{tabular}{|l|l|l|l|}
\hline Religion & Obese & Non Obese & Total \\
\hline Hindu & $52(47.1 \%)$ & $202(51.8 \%)$ & $254(50.8 \%)$ \\
\hline Sarna* & $46(41.8 \%)$ & $171(43.8 \%)$ & $217(43.4 \%)$ \\
\hline Muslim & $1(1.1 \%)$ & $2(0.6 \%)$ & $3(0.6 \%)$ \\
\hline Christian & $11(10 \%)$ & $15(3.8 \%)$ & $26(5.2 \%)$ \\
\hline Total & $110(21.9 \%)$ & $390(78.1 \%)$ & $500(100 \%)$ \\
\hline Chi square $=375.257$ & P value $=.001$ & \\
\hline
\end{tabular}

$*$ Sarna $=$ Local religion of Jharkhand 
To Find Out The Risk Factors And Complications Associated With Obesity Among Adults ...

Table 6: Prevalence of obesity according to risk factors

\begin{tabular}{|c|c|c|c|c|c|c|}
\hline \multicolumn{2}{|l|}{ Risk Factor } & Obese & Non- obese & Odds ratio & $95 \% \mathrm{CI}$ & $P$ value \\
\hline \multirow[b]{2}{*}{ Gender } & Male & $59(31 \%)$ & $131(69 \%)$ & \multirow[t]{2}{*}{2.342} & \multirow[t]{2}{*}{$1.521,3.605$} & \multirow[b]{2}{*}{.0001} \\
\hline & Female & $51(16.5 \%)$ & $259(83.5 \%)$ & & & \\
\hline \multirow[t]{3}{*}{ Literacy Status } & Literate & $95(24.7 \%)$ & $290(75.3 \%)$ & \multirow[t]{3}{*}{2.184} & \multirow[t]{3}{*}{$1.211,3.940$} & \multirow[t]{3}{*}{.007} \\
\hline & Iliterate & $15(13.1 \%)$ & $100(86.9 \%)$ & & & \\
\hline & No & $82(19.2 \%)$ & $345(80.8 \%)$ & & & \\
\hline \multirow[t]{2}{*}{ Junk Food } & Yes & $89(21.8 \%)$ & $319(78.2 \%)$ & \multirow[t]{2}{*}{.409} & \multirow[t]{2}{*}{$.229, .729$} & \multirow[t]{2}{*}{.003} \\
\hline & No & $21(22.8 \%)$ & $71(77.2 \%)$ & & & \\
\hline \multirow[t]{2}{*}{ Type of Diet } & Veg & $41(14.5 \%)$ & $241(85.5 \%)$ & \multirow[t]{2}{*}{.367} & \multirow[t]{2}{*}{$.237, .569$} & \multirow[t]{2}{*}{.001} \\
\hline & Non-Veg & $69(31.7 \%)$ & $149(68.3 \%)$ & & & \\
\hline
\end{tabular}

Table 7: Prevalence of obesity according to use of both alcohol and tobacco

\begin{tabular}{|c|c|c|c|c|c|}
\hline & & & obese & Non obese & Total \\
\hline \multirow{4}{*}{$\begin{array}{l}\text { Both(Alcohol } \\
\& \text { Tobacco) }\end{array}$} & \multirow[t]{2}{*}{ yes } & Count & 28 & 11 & 39 \\
\hline & & $\%$ & $84.8 \%$ & $2.4 \%$ & $7.8 \%$ \\
\hline & \multirow[t]{2}{*}{ No } & Count & 5 & 456 & 461 \\
\hline & & $\%$ & $15.2 \%$ & $97.6 \%$ & $92.2 \%$ \\
\hline \multirow{2}{*}{\multicolumn{2}{|c|}{ Total }} & Count & 33 & 467 & 500 \\
\hline & & $\%$ & $100.0 \%$ & $100.0 \%$ & $100.0 \%$ \\
\hline \multicolumn{4}{|c|}{ Chi square $=291.655$} & \multicolumn{2}{|c|}{$\mathrm{P}$ value $=.001$} \\
\hline
\end{tabular}

Table 8: Prevalence of obesity according to work

\begin{tabular}{|l|l|l|l|}
\hline Type of work & Obese & Non obese & Total \\
\hline Sedentary & $20(18.2 \%)$ & $124(31.8 \%)$ & $144(28.8 \%)$ \\
\hline Moderate & $72(65.4 \%)$ & $184(47.2 \%)$ & $256(51.2 \%)$ \\
\hline Heavy & $18(16.4 \%)$ & $82(21 \%)$ & $100(20 \%)$ \\
\hline Total & $110(22 \%)$ & $390(78 \%)$ & $500(100 \%)$ \\
\hline & Chi square $=12.050$ & P value $=.002$ & \\
\hline
\end{tabular}

Table 9: Prevalence of obesity according to Number of meal

\begin{tabular}{|l|l|l|l|}
\hline No of Meal & Obese & Non obese & Total \\
\hline$\leq 3$ & $38(34.5 \%)$ & $262(67.2 \%)$ & $300(60 \%)$ \\
\hline$>3$ & $72(65.5 \%)$ & $128(32.8 \%)$ & $200(40 \%)$ \\
\hline Total & $110(22 \%)$ & $390(78 \%)$ & $500(100 \%)$ \\
\hline & Chi square $=38.073$ & P value $=.001$ & \\
\hline
\end{tabular}

Table-10: Complicatios associated with obesity

\begin{tabular}{|c|c|c|c|c|c|}
\hline & & & obese & Non -obese & Total \\
\hline \multirow[t]{10}{*}{ Disease present } & \multirow[t]{2}{*}{ Hypertension } & Count & 31 & 11 & 42 \\
\hline & & $\%$ & $25.6 \%$ & $11.3 \%$ & $19.3 \%$ \\
\hline & \multirow[t]{2}{*}{ Diabetes Mellitus } & Count & 49 & 31 & 80 \\
\hline & & $\%$ & $40.5 \%$ & $32.0 \%$ & $36.7 \%$ \\
\hline & \multirow[t]{2}{*}{ Both(HTN \& DM) } & Count & 16 & 31 & 47 \\
\hline & & $\%$ & $13.2 \%$ & $32.0 \%$ & $21.6 \%$ \\
\hline & \multirow[t]{2}{*}{ Coronary heart disease } & Count & 10 & 6 & 16 \\
\hline & & $\%$ & $8.3 \%$ & $6.2 \%$ & $7.3 \%$ \\
\hline & \multirow[t]{2}{*}{ Rheumatoid arthritis } & Count & 15 & 18 & 33 \\
\hline & & $\%$ & $12.4 \%$ & $18.6 \%$ & $15.1 \%$ \\
\hline \multirow{2}{*}{\multicolumn{2}{|c|}{ Total }} & Count & 121 & 97 & 218 \\
\hline & & $\%$ & $100.0 \%$ & $100.0 \%$ & $100.0 \%$ \\
\hline \multicolumn{3}{|c|}{ Chi square $=17.200$} & \multicolumn{3}{|c|}{$\mathrm{P}$ value $=.002$} \\
\hline
\end{tabular}

Table 11: Binary logistic regression analysis of risk factors of obesity Factors

\begin{tabular}{|l|l|l|l|}
\hline Factors & Adjusted odds ratio & $95 \%$ C.I of adjusted odds ratio & P value \\
\hline Age & 1.854 & $1.484,2.316$ & $<0.05$ \\
\hline Literacy & 0.429 & $0.220,0.838$ & $<0.05$ \\
\hline Alcohol & 3.17 & $1.693,5.95$ & $<0.05$ \\
\hline Ses & 2.56 & $1.84,3.57$ & $<0.05$ \\
\hline Religion & 0.237 & $0.146,0.386$ & $<0.05$ \\
\hline Gender & 0.598 & $0.382,0.936$ & $<0.05$ \\
\hline Junk Food & $0.860,4.393$ & $<0.05$ \\
\hline
\end{tabular}


In the present study, those factors which were significant by univariate analysis(gender, Literacy, socioeconomic status, alcohol intake, type of diet, no. of meals per day and tobacco use) were taken for Binary logistic regression analysis, found that gender $(\mathrm{OR}=0.598,95 \%$ CI $=0.382,0.936)$, literacy status $(\mathrm{OR}=0.429,95 \% \mathrm{CI}=0.220,0.838)$, religion $(\mathrm{OR}=0.237,95 \% \mathrm{CI}=0.146,0.386)$, socio economic status $(\mathrm{OR}=$ $2.56,95 \% \mathrm{CI}=1.84,3.57)$ and alcohol intake(OR $=3.17,95 \% \mathrm{CI}=1.693,5.95)$ were significant variables for obesity among adults.

\section{Discussion}

The present cross sectional study was carried in areas of Namkum Block of Ranchi district among 500 adults aged 20years and above to determine the prevalence of obesity, its associated risk factors and complications associated with obesity.

Table 1: Shows, out of the total 500 study subjects,310(62\%) were females and 190(38\%) were males. The mean age was $42.75+18.87$ years with a range from 20 to 86 years. The mean age of males was $38.71+$ 17.17 years and of females $45.18+19.43$ years. There was poor representation of males in the study sample as most of them had gone to fields by the time we visit to villages.

Similar findings in a study conducted by Chythra R R ,Veena G K et al, ${ }^{(13)}$ among a rural population in coastal Southern Karnataka, India among individuals of either sex, aged 30 years and above was carried out on 1,239 respondents, out of which $434(35 \%)$ were males and $805(65 \%)$ were females. There was poor representation of males in the study sample as most of them were employed overseas or in the neighbouring states and many were involved in occupations such as fishing and unskilled daily wage labour and thus, were not available during the survey. ${ }^{(14)}$

Table 2: Shows ,out of total 500 study subjects ,268(53.7\%) were having BMI between 18.5-22.9, 110(21.9\%) were having BMI >25,91( 18.2\%) were having BMI between 23-24.9 and $31(6.2 \%)$ were undernourished having BMI less than 18.5.According to the Asia Pacific BMI guidelines, overall prevalence of obesity was $21.9 \%$ ( males-53.6\%,females-46.4\%), prevalence of pre obese/overweight was $18.2 \%$ (males$45 \%$,females-55\%), $53.7 \%$ were in the normal range (males-30.5\%, females-69.5\%) and $6.2 \%$ were under nourished(males- $25.8 \%$, females-74.2\%). Prevalence of overweight was higher among females compared to males, but prevalence of obesity was higher among males compared to females.

High prevalence of obesity in males may be due to life style related factors like increased consumption of alcohol and smoking with high intake of food rich in fat (i.e non vegetarian food). But a number of physiological processes are believed to contribute to an increased storage of fat in females. In a study conducted by Chythra C Rao and Kamat V et al ${ }^{(13)}$ reported that, prevalence of obesity (BMI> 30) was $6.6 \%$,over weight (BMI >25) was $21.4 \%$ according to WHO BMI classification. In a study conducted by Deshmukh P R et al, ${ }^{(15)}$ overall prevalence of obesity (According to WHO Asia-Pacific guidelines ,BMI > 25) was 5.13\%, out of which $5.1 \%$ in males, $5.2 \%$ in females, prevalence overweight(BMI >23) was $6.5 \%$, out of which $6.5 \%$ in males and $5.4 \%$ in females. In a study conducted by Anita $\mathrm{P}$ Naidu et al ${ }^{(16)}$ and $\mathrm{N}$ Gopinath et al prevalence rate was more in females compared to males. $\mathrm{N}$ Gopinath et al in their study observed that, the prevalence rate of obesity was more in females $(33.4 \%)$ compared to males $(21.3 \%) .{ }^{(17)}$ In a study conducted by, Anita P Naidu et al found that there were $60 \%$ obese female and $40 \%$ obese male subjects. In a study conducted by Haldiya K R et $\mathrm{al}^{(18)}$, overall prevalence of obesity (Asia pacific classification, BMI $>25$ ) was reported to be $26.2 \%$ (males $11.7 \%$,females $14.5 \%$ ).

Similar findings In a study conducted by Rao C C et al over all prevalence of central obesity was $51.7 \%$.out of which $18.0 \%$ and $69.8 \%$ among males and females respectively .

Table 3: Shows, prevalence of obesity was higher among $41-50$ years age group (35\%) followed by 20-30 years age group (30\%), 51-60 \& 71-80 years age group (10\%) and 61-70 years age group (9.1\%) and 6170 years age group ( $7.3 \%$ ). Difference in the prevalence of obesity among different age groups was found to be statistically significant. Similar observations were made by Sunita Asthana et al ${ }^{(20)}$ and N Gopinath et al ${ }^{(19)}$ found a direct relationship between age and prevalence of obesity. Prevalence of obesity showed an increasing trend over the successive age period. Prevalence of obesity increased from 8\% in 15-20years age group to 50\% in women aged 50 years and above. The prevalence was highest in the age group 40 years and above. As per NFHS-2(1998-1999), the prevalence of obesity in females increased with increasing age. Lowest prevalence rate of 0.45 was found in the age group of 20-24years and highest prevalence of $3.9 \%$ was found in the age group of $35-49$ years and the overall prevalence was $5.8 \% 26$. With increase in age, physiologically there is decrease in the metabolic rate and increase in the sedentary lifestyle contributing to increase in obesity.

Table 4: Shows, out of 500 subjects, prevalence of obesity among upper class was $3.6 \%$, upper middle class was $27.2 \%$, middle class was $31.8 \%$, lower middle class was $28.2 \%$ and lower class was $9.2 \%$. Difference in the prevalence of obesity across the socioeconomic status was found to be statistically significant.Similar 
findings In a study conducted by Rao $\mathrm{CR}$ and Kamat $\mathrm{V}$ et al ${ }^{(13)}$,i.e.significant association between socioeconomic status and prevalence of obesity.

Table 5: Shows, prevalence of obesity was higher among Hindu(47.2\%) followed by in Sarna $(41.8 \%)$ and in Christian (10\%)and was found to be statistically significant.

Similar findings In a study conducted by $\mathrm{C}$ R et al ${ }^{(13)}$ among People having sedentary and light physical activity had BMI $\geq 30 \mathrm{~kg} / \mathrm{m} 2$ among Christians and Hindus 4 (10.8\%) and 34 (6.3\%) individuals had BMI $\geq 30$ $\mathrm{kg} / \mathrm{m} 2$ respectively.

Table 6: Shows the strength of association of various risk factors attributed to obesity and was found to be statistically significant.

Table 7: Shows relationship between both (alcohol \& tobacco) use and prevalence of obesity was found to be statistically significant.

Table 8: shows, prevalence of obesity among sedentary workers was $18.2 \%$,moderate workers was $65.4 \%$ and $16.4 \%$ among heavy workers. Difference was found to be statistically significant.

$\mathrm{N}$ Gopinath et $\mathrm{al}^{(19)}$ in their study ,observed $29.3 \%$ prevalence of obesity among sedentary activity group and 24.55 in moderate activity group and 17.5 in heavy activity group.

Anita P Naidu et al ${ }^{(16)}$ found that, obesity was relatively more in the subjects doing sedentary work. They observed that 955 of male obese and 965 of female obese subjects were sedentary workers.Sedentary work demands considerably less energy when compared to moderate work. A positive energy balance occurs, if calorie intake remains higher than requirement. If this positive energy balance persists for long term can lead to weight and obesity.

Table 9: Shows prevalence of obesity according to number of meals and was found to be statistically significant.

Table 10: Shows complications associated with obesity and was found to be statistically significant.

Table 11 :Shows, Binary logistic regression analysis was done using enter method, found that gender, literacy status ,religion, socio economic status and alcohol intake were significant variables for obesity among rural adults. In a study conducted by $\mathrm{C} \mathrm{R}$ et al. ${ }^{(13)}$ observed that multiple logistic regression revealed literacy up to secondary education (adjusted $\mathrm{OR}=3.42,95 \% \mathrm{CI}=1.34,8.69$ ) and graduation (adjusted $\mathrm{OR}=7.58,95 \%$ $\mathrm{CI}=2.53,22.71$ ), as significant variables for obesity (BMI classification)

In a study conducted by Zhang $\mathrm{X}$ et $\mathrm{al}^{(21)}$ Multivariable logistic regression revealed certain risk factors of obesity that included being a women, Mongolian nationality and education status of over junior high school level. Moderate physical activity alone was shown as protective factor.

\section{Conclusion}

A community based cross-sectional study conducted in urban areas of Namkum Block, Ranchi district having population of 1,45,841(Census 2011) distributed over 92 villages from September 2013 to December 2015. Finally to conclude, obesity has no longer remained a problem of only upper socio economic class but Indian middle class has also dragged into the so called "problem of affluent." In simple terms, obesity is a consequence of an energy imbalance; energy intake exceeds energy expenditure over a considerable period. Obesity is commonly seen as a complex multi factorial disease, it is a condition resulting from a lifestyle that promotes a positive energy balance, but also one that becomes manifest more readily in people who have an inherited susceptibility to be in positive energy balance.

Obesity can be seen as the first wave of a defined cluster of non-communicable diseases now observed in both developed and developing countries. This has been called the 'New World Syndrome' is responsible for disproportionately high levels of morbidity and mortality in newly industrialized countries. Thus, while obesity is viewed by health professionals from a medical perspective, it also needs to be recognized as a symptom of a much larger global social problem.

\section{References}

[1]. Pednekar MS. Association of body mass index with all-cause and cause-specific mortality: Findings from a prospective cohort study in Mumbai (Bombay), India. Int J Epidemiol 2008;37:524-35.

[2]. Clinical guidelines on the identification, evaluation and treatment of overweight and obesity in adults: the evidence report. National Heart, Lung and Blood Institute in cooperation with the National Institute of Diabetes and Digestive and Kidney Diseases. URL available from: www. nhlbi. nih. gov/ guidelines /obesity/e_txtbk. accessed on 25.07.2012. 18.10

[3]. Jensen GL, Friedmann JM. Obesity is associated with functional decline in community-dwelling rural older persons. J Am Geriatr Soc. 2002;50:918 -23.

[4]. Chen H, Bermudez OI, Tucker KL. Waist circumference and weight change are associated with disability among Elderly Hispanics. J Gerontol A Biol Sci Med Sci 2002;57:M19-25.

[5]. Prentice AM, Jebb SA. Beyond body mass index. Obes Rev 2001;2(3):141-47.

[6]. Carmelli D, Mc Elroy MR, Rosenman RH. Longitudinal changes in fat distribution in the Western Collaborative Group Study: a 23 year follow up. Int J Obes 1991, 15(1):67-74.

[7]. Abolfotouh MA, Daffallah AA, Khan MY, Khattab MS, Abdulmoneim. Central obesity in elderly individuals in South Western Saudi Arabia: prevalence and associated morbidity. Eastern Mediterranean Health Jounal 2001;7(4/5):716- 724. 
[8]. The Global Challenge of Obesity and the International Obesity Task Force (international union of nutritional sciences).available from www.iunsweb.org/the-global-challenge-of-obesity-and-the international -obesity-task-force(accessed on 13.07.12)

[9]. World Health Organization, Regional Office for South-East Asia. Non communicable diseases in the South-East Asia Region: Situation and response 2011, http://www.searo.who.int/linkfiles/sde_rep-2011-dec.pdf (accessed on 24.07.2012)

[10]. Mohan V, Sandeep S, Deepa R, Shah B, Varghese C. Epidemiology of type 2 diabetes: Indian scenario. Indian J Med Res 2007;125:217-30.

[11]. Gupta R. Burden of coronary heart disease in India. Indian Heart J 2005;57:632-8.

[12]. Gupta R. Coronary heart disease in India: Absolute numbers and economic burden. Rapid response to Ghaffar A, Reddy KS, Singhi M. Burden of noncommunicable diseases in South Asia. BMJ 2004;328:807-10

[13]. Rao CR, Kamath VG, Shetty A, Kamath A. A cross-sectional analysis of obesity among a rural population in coastal Southern Karnataka, India. AMJ 2011, 4, 1, 53-57.

[14]. Martin AD, Drinkwater DT, Clarys JP, Ross WD. Cadaver study challenges body fat computations. Phys Sports Med 1981;9:21-7.

[15]. Deshmukh PR, Gupta SS, Dongre MS, Bharambe C ,Maliye C, Kaur S et al. Relationship of anthropometric indicators with blood pressure levels in rural Wardha. Indian J Med Res 2006:657-64.

[16]. Naidu PA, Musthari BJ, .Demographic profile and food behaviour in selected obese adults.The Ind J Nutr Dietet 1993;199330;154158 .

[17]. Lean ME, Han TS, Morrison CE. Waist circumference as a measure for indicating need for weight management. BMJ 1995;31:15861.

[18]. Haldiya K R ,Murli L,Mathur and Sachadev R. Lifestyle related risk factors for cardiovascular disease in a desert population of India.

[19]. Gopinath N, Chadha SL, Jain P , Shekhawat S, Tandon R. An epidemiological study of obesity in adults in the urban population of Delhi.J Assoc Physicians India 1994;42(3):212-15.

[20]. Sunita Asthana ,Gupta Vm. Role of biological factors in the development of obesity. The Ind JNutr Dietet 1999; 36:263-267.

[21]. Zhang X, Sun Z, Zhang X, Zheng L, Liu S, Xu C et al. Prevalence and associated factors of overweight and obesity in older rural Chinese population. Intern Med J. 2008 Jul; 38(7):580-6. 